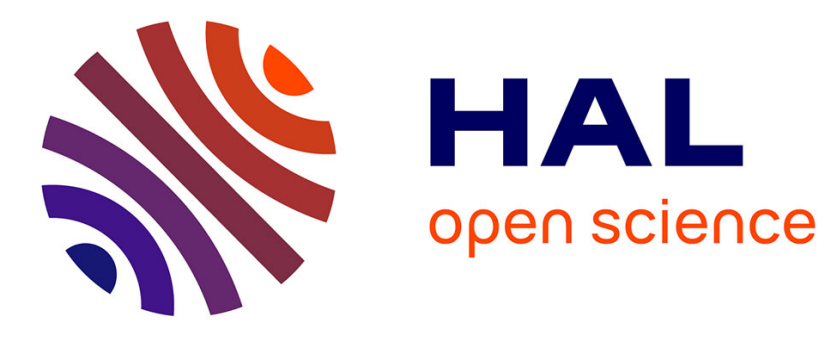

\title{
Flexibility evaluation: A toolbox approach
}

Konstantinos Georgoulias, Nikolaos Papakostas, Dimitris Mourtzis, George

Chryssolouris

\section{To cite this version:}

Konstantinos Georgoulias, Nikolaos Papakostas, Dimitris Mourtzis, George Chryssolouris. Flexibility evaluation: A toolbox approach. International Journal of Computer Integrated Manufacturing, 2009, 22 (05), pp.428-442. 10.1080/09511920802527582 . hal-00513411

\section{HAL Id: hal-00513411 \\ https://hal.science/hal-00513411}

Submitted on 1 Sep 2010

HAL is a multi-disciplinary open access archive for the deposit and dissemination of scientific research documents, whether they are published or not. The documents may come from teaching and research institutions in France or abroad, or from public or private research centers.
L'archive ouverte pluridisciplinaire HAL, est destinée au dépôt et à la diffusion de documents scientifiques de niveau recherche, publiés ou non, émanant des établissements d'enseignement et de recherche français ou étrangers, des laboratoires publics ou privés. 


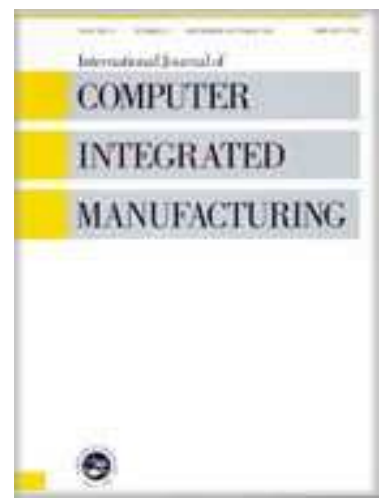

\section{Flexibility evaluation: A toolbox approach}

\begin{tabular}{|r|l|}
\hline Journal: & International Journal of Computer Integrated Manufacturing \\
\hline Manuscript ID: & TCIM-2007-IJCIM-0160.R1 \\
\hline Manuscript Type: & Original Manuscript \\
\hline Date Submitted by the & 07-Aug-2008 \\
\hline Complete List of Authors: & $\begin{array}{l}\text { Georgoulias, Konstantinos; University of Patras, Laboratory for } \\
\text { Manufacturing Systems and Automation } \\
\text { Papakostas, Nikolaos; University of Patras, Laboratory for } \\
\text { Manufacturing Systems and Automation } \\
\text { Mourtzis, Dimitris; University of Patras, Laboratory for } \\
\text { Manufacturing Systems and Automation } \\
\text { Chryssolouris, George; University of Patras, Laboratory for } \\
\text { Manufacturing Systems and Automation }\end{array}$ \\
\hline Keywords: & FLEXIBILITY, MANUFACTURING SYSTEMS, FLEXIBILITY MEASURES \\
\hline Keywords (user): & FLEXIBILITY EVALUATION \\
\hline
\end{tabular}

\section{S ScholaroNE" \\ Manuscript Central}




\title{
Flexibility Evaluation: A Toolbox Approach
}

\author{
K. GEORGOULIAS, N. PAPAKOSTAS, D. MOURTZIS AND G. \\ CHRYSSOLOURIS*
}

\begin{abstract}
Laboratory for Manufacturing Systems and Automation, Department of Mechanical Engineering and Aeronautics, University of Patras, 26500 Rio, Patras, Greece, Tel.: +30 2610997262 , Fax: +30 2610997744
\end{abstract}

Flexibility is an important aspect of modern manufacturing systems. Although a system's capability to monitor, predict and improve flexibility has long been considered as a major competitive advantage, the development of methods and algorithms for the measurement of manufacturing flexibility remains an open issue both from an academic and an industrial point of view. The purpose of this work is to propose a holistic approach for short, mid and long-term flexibility performance measuring and monitoring in industrial practice. In the core of the suggested approach, stands a flexibility evaluation toolbox, which can be utilized for real-life industrial cases.

Keywords: Flexibility; Manufacturing systems; Flexibility evaluation

\footnotetext{
**Corresponding author. Email: xrisol@1ms.mech.upatras.gr
} 


\section{Introduction}

Modern manufacturing systems are faced with continuous changes in the environment they operate. These changes included the rapid introduction of new products, abrupt changes in product demand and mix, and more frequent modifications to existing products (Spicer et al 2002). The environment in which companies operate is highly turbulent (Westkämper 2007). Shorter product lifecycles, increased numbers of new models as well as variants, uncertainties and fluctuations in the market demand, are some reasons that have forced engineers to consider flexibility as an important aspect of the manufacturing systems. Nevertheless, in order for flexibility to be considered in the design and operation phase, it should be defined in quantifiable terms (Chryssolouris 2005). Current tools for monitoring complex production systems base their decisionmaking functionality on calculations of key performance indicators, such as utilization, delivery time, cost related figures and others. However, they lack in indications regarding the installed and potential flexibility of the system.

Mathematical programming, dynamic programming optimization techniques and queuing theory have been widely used over the past years as modelling and analysis tools for studying the behaviour of production systems (Chryssolouris 2005). In PeláezIbarrondo and Ruiz-Mercader (2001) a method to measure the level of mix flexibility and volume flexibility in an integrated way, was presented. Their proposed index, defined by the authors as operational flexibility, integrated both the mix and volume flexibility. Ramasesh et. al. (2001) developed a quantitative analysis framework and a simulation methodology to explore the value of agility in financial terms. Pereira and Paulré (2001) presented a method of assessing the flexibility of a production system, 
based on the concept of the system's adaptation to the environment. Wiendahl and Heger (2004) proposed a method of justifying changeability in economical terms, using the scenario planning technique. Recently, supply chain flexibility has gained more interest. Some interesting findings are provided in Graves and Tomlin (2003) who examined process flexibility in multi-product supply chains facing uncertain demand. They identified the main inefficiencies and based on this, they have developed a flexibility measure. They stated that higher values of this measure represented increased efficiency of the supply chain, by surpassing the identified bottlenecks.

Chryssolouris $(1992 ; 2005)$ suggested that the 'flexibility of a manufacturing system is determined by its sensitivity to change' and it is evaluated by calculating the expected cost of accommodating possible changes in the operating environment. The smaller the expected change cost is, the less sensitive the system is to changes in its operating environment and thus, the system is considered as more flexible. Bateman et al. (1999) have extended the 'sensitivity to change' approach while Alexopoulos et al. (2005a) have applied this approach to a real case study of the commercial refrigerators production industry. Chryssolouris et al. (1998) have proposed a measure of flexibility, based on the calculation of the transfer function of the manufacturing system. The transfer function describes the way a manufacturing system responds to changes in the input, i.e. to various orders of different products and to different volumes, in the same manner as the transfer function characterizes a simple mechanical system, which responds under the excitation of a force, vibrating over time.

Many academic publications have pointed out that the quantification of flexibility, even though approaches for its evaluation in the investment decision-making are few, is difficult to be handled and mostly limited to special cases (Abele et al 2006). Even if a 
number of methods have been presented in literature for flexibility measurement, most of these approaches are difficult to be incorporated into software solutions and production engineers sometimes consider them as too time-consuming for manual execution. In the academic work, mathematical tools are often used for the complex calculations required by most of the measures. These tools provide some assistance on the calculation part but they do not automate the overall process; neither do they provide meaningful identifications nor definitions of the results.

Commercially available solutions mostly aim at providing change management and data collection support. Their functionality mainly focuses on the formalization and support of the required change processes by employing a standardized sequence of actions together with efficient data control in order for the complexity of the change procedures to be addressed. Their main objective is to monitor the change efforts and secure the necessary conditions for the successful introduction of the change to all the affected levels of the production enterprise.

However, the currently available commercial solutions neither measure nor consider flexibility when providing change management support. This occurs due to the fact that they are not capable of measuring flexibility in the real industrial and business environment. In fact, the applicability of flexibility measures to the real industrial environment is either rare or limited only to specific situations. Additionally, since flexibility is a subject difficult to be quantified, this invigorates the absence of comprehensive flexibility measurements from the commercial solutions available. Furthermore, the state of the art very being large and heterogeneous, makes the comparison of different existing solutions infeasible. So, the development of real case 
applications, is at present, the proper test bed for the assessment of new methodologies (Carpanzano and Jovane 2007).

The presented approach aims at addressing these issues in order to narrow the gaps identified previously. By providing decision support capabilities, based on flexibility measurements and by automating the overall flexibility evaluation process, the approach presented is expected to assist production engineers as well as to increase the applicability of flexibility consideration to a variety of real-life industrial situations.

\section{Flexibility measurements in change management}

An approach to the consideration of flexibility measurements, in the operation and management of modern production systems and production networks, is presented in Figure 1. In this figure, the technical approach for the implementation of the proposed platform is shown.

[Please insert Figure 1 about here]

Three main entities are identified:

1. Flexibility evaluator: This module lies in the core of the proposed approach. The knowledge regarding the available and potential flexibility of the production system is crucial to the lifecycle management decision-making process. This is provided by the flexibility evaluation toolbox, which is further described below.

2. Data collector: The data collector and the processor module are used for importing and exporting data from the overall system.

3. Change management process: Both the flexibility evaluator and the data collector/processor communicate with the change management process module. 
Through this module, the user is able to define, monitor and initiate management change processes by using the utilities provided by the platform.

\subsection{Flexibility evaluation}

Apart from its integration into the root platform, the flexibility evaluator module can also be used as a stand alone application. Its objective is to provide quantified flexibility measurements in all user-defined cases.

A real challenge in devising applicable flexibility measures is to develop models and algorithms that can deliver meaningful results with modest data requirements. Models with vast data requirements tend to be complex and time consuming to be analysed. An approach to overcome this issue is presented by Alexopoulos et. al. (2006), where real or near real time monitoring of the data related to various manufacturing parameters, gathered during the operation of a production system, are incorporated in order to provide eventually the flexibility performance of a production system. This approach has been motivated by the well-established dynamic behaviour analogy between a mechanical and a manufacturing system (Chryssolouris 1996, Chryssolouris et al. 1998).

As aforementioned, due to its early recognition as an important attribute of manufacturing systems, flexibility measurement has been a lively area of research that has resulted in the development of numerous methods and techniques for its quantification. Kochikar and Narendran (1992) introduced a framework for assessing the flexibility of manufacturing systems, while Mohamed et al (2001) investigated the effect of changing a machine's flexibility on the performance measures of a flexible manufacturing system. Hobbs et al (1994) proposed a measure called the relative 
flexibility benefit to capture the benefit or cost-savings in contrasting, how well a system performs under a single set of expected future conditions, against how well it performs, on average, if all possible conditions and their probabilities have been considered. The relative flexibility benefit is not possible to be distinguished between investments with different degrees of flexibility. The normalised flexibility measure of Schneeweiss and Kühn (1990) is intended for the comparison of more than two options. Wahab et al (2001) developed a domain- independent framework to measure the dynamic flexibility of manufacturing systems, based on a super efficiency DEA (Data Envelopment Analysis) model. Colledanil and Tolio (2005) proposed a general approximate analytical method to support the configuration / reconfiguration of production system capable of modelling three different types of machines, namely: dedicated manufacturing machines, flexible manufacturing machines, and assembly/disassembly machines. Peláez-Ibarrondo and Ruiz-Mercader (2001) conducted a research aiming to develop a methodology for measuring the level of mix flexibility and volume flexibility in an integrated way, while Shuiabia et al (2005) proposed entropy as a measure of flexibility for manufacturing operations.

Nevertheless, it is quite hard to cover the requirements of a wide range of applications with a single measure only. In order to overcome this challenge, a flexibility evaluation toolbox has been developed by Georgoulias et al. (2007). A number of individual flexibility measures compose the flexibility evaluation toolbox. Based on the specific requirements of each case, the production engineers are able to use the most suitable flexibility measure, taking into consideration the special characteristics of the industrial case under study. 
Depending on the flexibility measure that is to be used, the toolbox has to be provided with the appropriate data. The data collector module, as described in the next paragraph, handles this task. The output of this module is a flexibility evaluation report, based on the individual flexibility measure that was used and the indicators that the production engineer would wish to rely on. The flexibility evaluator is the core of the whole concept and the data collector and change management process modules adapt to its requirements. The flexibility evaluation toolbox is presented in Figure 2. Five individual flexibility measures are integrated into the flexibility evaluation toolbox: The POC (Chryssolouris and Lee 1992, Chryssolouris 1996, Alexopoulos et al. 2005a), the $\zeta$-analogy method ( Chryssolouris 1996, Bechrakis et al. 1997, Chryssolouris et al. 1998), the Desyma (Alexopoulos et al. 2005b, Alexopoulos et al. 2007a), the FLEXIMAC (Alexopoulos et al. 2006) and the oscillator analogy (Alexopoulos et al. 2007b).

[Please insert Figure 2 about here]

Short descriptions of the aforementioned measures are provided hereafter:

The Penalty of Change (POC) is a generic measure since it can be applied to different flexibility types and combines both technological and economical terms. The lower the POC is, the higher the flexibility. The POC can therefore be defined as:

$$
\mathrm{POC}=\sum_{i=1}^{D} \operatorname{Pn}\left(X_{i}\right) \operatorname{Pr}\left(X_{i}\right)
$$

Where:

$\mathrm{D}$ is the number of potential changes

$\mathrm{Xi}$ is the ith potential change

$\mathrm{Pn}(\mathrm{Xi})$ is the penalty cost of the ith potential change

$\operatorname{Pr}(\mathrm{Xi})$ is the probability of the ith potential change to occur 
DESYMA (Design of Systems for Manufacture) is another approach based on measuring flexibility with the help of demand probabilities. It further combines economic measures, sensitivity analysis and manufacturing performance measures in an integrated manner. The Discounted Cash Flow (DCF) of the system is calculated for each market scenario and the spread of the DCF scores defines the flexibility of the system in the given market environment. The problem of calculating the minimum DCF can be formulated as follows:

Subject to

$$
D C F_{\mathrm{i}}=\operatorname{In} v+\operatorname{minimize}\left\{\sum_{t=1}^{T} \frac{\left\{O_{m}(t)+S_{k m}(t)\right\}}{(1+r)^{t}}\right\}
$$

$\mathrm{Cm} \geq \operatorname{Di}(\mathrm{t}) \forall \mathrm{t} \in[1 \ldots \mathrm{T}], \mathrm{m} \in[1 \ldots \mathrm{M}]$ and $\mathrm{i} \in[1 \ldots \mathrm{S}]$

Where:

DCFi: is the minimum Discounted Cash Flow score for market scenario Di, $i \in[1 \ldots S]$

Inv: is the investment cost which occurs at period $\mathrm{t}=0$

$\mathrm{Om}(\mathrm{t})$ : is the total cost for period $\mathrm{t}$ if configuration Confm is assigned for period $\mathrm{t}$

$\operatorname{Skm}(\mathrm{t})$ : is the switching cost for period $\mathrm{t}$ if configuration $\mathrm{k} \in[1 \ldots \mathrm{M}]$ is assigned for period $\mathrm{t}-1$ and configuration $\mathrm{m} \in[1 \ldots \mathrm{M}]$ is assigned for period $\mathrm{t}$

$\mathrm{Cm}$ : is the capacity of the selected configuration $(\mathrm{m} \in[1 \ldots \mathrm{M}])$ for period $\mathrm{t}$

$\operatorname{Di}(t)$ : is the demand at period $t$ according to scenario $\mathrm{Di}, \mathrm{i} \in[1 \ldots \mathrm{S}]$

$\mathrm{T}$ : the total number of periods and

$\mathrm{r}$ : is the interest rate which remains constant for whole $\mathrm{T}$ 
The ' $\zeta$-analogy' method makes use of the established $\zeta$-analogy between a manufacturing and a mechanical system. The higher the damping factor $\zeta$ is in a mechanical system, the less sensitive is its response to changes in the input/excitation, while the lower the value of $\zeta$, the more sensitive is the response of the system to changes in the input. This damping factor $\zeta$ can also be estimated from the frequency spectrum of the system as:

$$
\zeta \approx \frac{1}{2 Q}
$$

Where $\mathrm{Q}$ is the amplitude in the frequency spectrum that corresponds to the fundamental natural frequency.

FLEXIMAC is a dimensionless factor, in the same manner as the well-defined in literature, quality measurement, named as process capability index $\mathrm{Cp}$ (Chryssolouris 2005). FLEXIMAC can be valuable for comparing different production systems when they are exposed to the similar excitation from the external environment. The higher the value of FLEXIMAC is in a manufacturing system, the less sensitive the system may be considered to changes in the input and thus, more flexible. FLEXIMAC is calculated by finding the system's eigenvalues $\Omega \mathrm{i}$ and calculating the amplitude Qi on those $\Omega \mathrm{i}$ frequencies. FLEXIMAC is then calculated as an average value of the ten largest Qi.

$$
\text { FLEXIMAC }=\frac{1}{10} \sum_{i=1}^{10}\left(\frac{1}{2 Q_{i}}\right)
$$


The oscillator analogy method is an approach to modeling and analysis of the dynamic behavior of manufacturing systems. The manufacturing system is considered responding to an excitation, namely a demand that varies over time, by producing a number of parts over time. A definition for assessing the manufacturing flexibility, based on this approach, is discussed here. Since flexibility in a manufacturing system is considered its ability to quickly increase its production rate and respond to changes in the demand, it is expected that flexibility in a manufacturing system will also be proportional to $m, c$ and $k$, in the same way as it is the time required by the mechanical system to reach its first peak. Thus, we can define flexibility by using the $m, c$ and $k$ attributes in the following manner:

$$
\text { flexibility }=f\left(\frac{k}{m \cdot c}\right)
$$

The process of the flexibility evaluation is demonstrated in Figure 3. Small variations in the results may be realized when using different measures. The basic steps for the flexibility evaluation are described hereafter. The required data set has been initially prepared. This set consists of information gathered from the production system and information on the external demand, placed or expected to be placed upon the manufacturing system. Based on the information available, the characteristics of each case and the preferences of the user, the required data set is passed to the most appropriate flexibility measure of the flexibility evaluation toolbox. It is then that the execution of the necessary calculations takes place. Depending on the measure which has been utilized, the value of the related flexibility indicator is calculated and elaborated. The final flexibility evaluation report is provided with the results.

[Please insert Figure 3 about here] 
As stated above, the utilization of the flexibility evaluation toolbox enables the user to address a wide range of situations. As it is shown in Figure 4, the selected measures can be used to address a wide range of cases (Georgoulias et al. 2007). In fact, they all act as complementary to each other. In order to describe the elements of this figure, we start with the enterprise level fields, where the applicability of each measure to the various enterprise levels is provided. In the next rows, the flexibility types that can be addressed by each measure are shown, whilst the complexity of the required data of each measure is also identified. Moreover, the possibility of aggregating the measures among different production levels is provided. The measures can be used in order to provide short-term up to long-term flexibility evaluations. This can be further realised when thinking of near real-time flexibility monitoring in contrast to flexibility evaluation, based on forecasted future demands. The classification of the measures, based on the ease of their application and the use of a transfer function approach, is also provided.

[Please insert Figure 4 about here]

The classification table of the flexibility measures provided in Figure 4 is separated into 7 discrete fields/ categories: Enterprise Level, Flexibility Type, Required Data Complexity, Possible Aggregation, Chronological Scale, Ease of Application and Transfer Function. The following paragraphs are dedicated to explaining the classification of each measure in each of the aforementioned fields. It should be noted that the classification provided is not obligatory and the user is not restricted to using the measures only as indicated in the classification table. Depending mainly on the 
specifics of each situation at hand, the flexibility evaluation toolbox provides the opportunity of selecting the most appropriate measure for application, even if it does not come to absolute agreement with the presented classification. The availability of the data and quality may as well be the main criteria on which the measure should be made. Therefore, the classification is considered as the first step in the construction of application guidelines, but further research is required for finalizing and verifying this classification.

The POC is based on the calculation of the financial penalty of an externally generated change in the system under study. The execution of the measure's calculations is not affected by the nature of the system or the potential change considered and thus, it can be applied to systems of any enterprise level, and utilized in possible aggregations, to measure different flexibility types, since the flexibility type measured is reflected in the change considered. The simplicity of the data input necessary and the fact that the POC calculation does not involve a transfer function makes the measure easily applicable. The POC can be used within any chronological scale, but should be preferred for midor long- term considerations.

Desyma measures flexibility with the help of demand probabilities and discounted cash flows. It is preferably applied to cases of lines and work places or to the case of "work place to line" aggregation in order for the product or volume/capacity flexibility to be measured. This is due to the nature of the more complex data input and calculations required. The calculations, despite not involving transfer functions, they can be demanding and together with the complexity of the data afflict the easiness of applying Desyma. As far as the chronological scale of possible cases is concerned, Desyma can be applied under virtually all circumstances, but it is more purposive for mid or long- 
term considerations, firstly because of the increased volume and quality of data, usually available in such cases, and secondly because the results of the measures are more useful to stakeholders in such decisions since they may consider alternative future scenarios.

The $\zeta$-analogy is most suitable for measuring the product or volume flexibility at factory, workplace or line level and in cases of aggregations. The measure's method is based on transfer function calculations, but the ease of application still remains mediocre due to the fact that the data input required is of low complexity, and can be obtained by measuring certain system parameters. The measure is quite suitable for utilization in short-term considerations, firstly because it can sufficiently provide the current state of the system under study, and also because the flexibility measurements can result from the recently obtained data.

FLEXIMAC is a highly generic measure, since the nature of the system in terms of size, enterprise level, aggregation etc. does not influence the method's applicability. Furthermore, FLEXIMAC can be used for the consideration of product, operation or volume/capacity flexibility, since the flexibility type measured is defined by the characteristics and the objectives of the case and does not affect the calculating method. The necessary data input consists of easily acquired measurements and, although the measure entails transfer function concepts, it is characterized by a medium level ease of application. The measure is most suitable for short-term considerations, firstly, because it can successfully portray the present state of a system and secondly, because the use of the recent data generate the results best utilized in such situations.

The oscillator analogy, such as POC and FLEXIMAC, is a highly generic measure whose applicability is independent of the system's' size, enterprise level, aggregation etc 
considered. The oscillator analogy can be utilized for measuring any type of flexibility since the flexibility type measured is reflected in the characteristics and the objectives of the case and does not affect the execution of the calculations. The data input required consists of system measurements that are usually relatively easy to obtain, depending on the system and the case at hand. The utilization of the oscillator analogy is preferable in short-term cases, and sometimes mid-term considerations, since its results are usually more valuable to stakeholders when they are generated by recently obtained data.

\subsection{Data collection}

Accurate and timely data selection from the various vertical and horizontal enterprise levels is essential. In extended enterprises, it is often perceived that the quality and usability of the underlying 'islands of data' cannot be ensured. Among the primary reasons for this are the lack of data standards across the enterprise levels, late submissions/arrivals of data, data asynchronies, human errors, and of course the large number of data collection sources. Furthermore, in change procedures, the complexity of the required data and the need for real or near real time information add another constraint to the efficient data collection. The data collector module aims at addressing these issues. The data collector module enables each company to utilize the proposed toolbox in a standard way: to possess a detailed description of the data that has to be recorded, to identify a specific kind of measurement for each performance and to validate the observations, with respect to the particular characteristics of the company and the related industry sector. This is the basis for successfully measuring the flexibility aspects of the manufacturing enterprise and for supporting the change management process. 
In parallel with the standardization, the data collector module assists the data recording and fetching from the various information sources. Since a large variety of sources could eventually be utilized to provide the necessary information, such as already installed ERP systems, knowledge bases, legacy databases, machinery interfaces, hardware sensors, smart tags, RFID tags, specialized staff etc., the data collector module assists in recording and selecting data from these sources by ensuring that the provided information is in line with the standardization followed and by employing mechanisms of automated data gathering when possible.

\subsection{Change Management Process}

Both the flexibility evaluator and the data collector modules are connected with the change management process module. Through this platform, the user is able to define, monitor and initiate change management processes by using the utilities provided.

When an internal or external disturbance occurs, the production system has to respond to this disturbance. At this point, a number of questions arise: Is the system capable of responding? Is it worth responding? How should the system respond? What has to be improved? Are the potential solutions feasible? Which procedure should be followed for the change to take place? The integration of the flexibility evaluation to the change management platform aims to support the engineers in charge to answer these questions. By having an insight about the available flexibility of the production system, the aforementioned questions will be easier to be answered. For example, by knowing the flexibility of the production system, the engineer in charge will be able to estimate the costs of the various change options and select the most appropriate response to the disturbance. This way, the flexibility evaluation is expected to provide the direction that the change management process should follow. 
Moreover, flexibility monitoring provides an overview to the production engineers on what has to be changed in order for the flexibility of their production systems to be increased. Following the flexibility evaluator results, machines, production lines, and even factories with low flexibility rating could be identified and a change process to ameliorate their flexibility could be defined.

The concept for the integration of the flexibility evaluation toolbox into change management and decision-making is shown in Figure 5.

[Please insert Figure 5 about here]

\section{System design}

In order to facilitate interoperability with information systems existing in the industry, the proposed platform is being developed as an open, modular software framework. The platform is planned to run on a central server, which hosts a database server, an application server, and a web-server. The platform has access to a database system by using modern database interface standards (e.g. JDBC, JDO), which keep the platform flexible and open to the use of different database systems. The change processes, which are supported by the platform, are performed by a process modelling engine, which can be easily configured. This approach keeps the platform open to individual change process definitions. A generalized user interface allows the use of different front-end types (web-based, mobile phone, etc.), thus providing an open user interface. The most important aspect for the openness of the platform is the flexible integration of external information sources (information systems, databases, sensor data). The use of modern interface standards (RMI, XML, and especially Web Services) may potentially reduce the efforts for integration to a minimum. 


\section{Conceptual Case Study}

In the case study discussed hereafter, the FLEXIMAC method is utilized from the flexibility evaluation toolbox to evaluate the flexibility of a production system in several simulations. For each simulation/experiment, the characteristics of the production system have been altered in order to simulate different levels of flexibility. The purpose of this paragraph is to demonstrate the way that FLEXIMAC could be used for measuring the flexibility of different productions systems, by using simple to gather, uncomplicated data. Additionally, the results of FLEXIMAC are validated, since the simulated production systems actually represent different levels of flexibility.

A job shop that processes two parts P1 and P2 to eventually produce the final product has been simulated. Part P1 is processed in the departments D1, D2, D3, while Part P2 is processed in the departments D1, D4, D5, D6. Both parts are then assembled in D7 in order to form the final product as shown in Figure 6.

Two sets of experiments have been conducted to demonstrate the application of the FLEXIMAC method for measuring the system's flexibility. For all experiments the processing times of the departments were assumed to be normally distributed with a mean value $\mu=5$ and a standard deviation $\sigma=1$. The setup times were also assumed to be normally distributed but with various mean values and standard deviations in each case. These variations have been set in order to simulate several cases of job shops with different flexibility, since it is assumed that a setup time increase results in decreasing the system's flexibility.

[Please insert Figure 6 about here] 
The FLEXIMAC method is applied to measure the flexibility of the system in a set of different cases. According to the approach proposed in this paper, the data collector module handles the recording and collection of the Cumulative Processing and Cumulative Flow Times (CPT/CFT) required by the FLEXIMAC method for each experiment.

The primary objective of this series of experiments is to determine the effect that the changing of the setup time has on the measure of FLEXIMAC for the system's flexibility. The experiments conducted were organized into two sets. Set 1 consists of experiments 1-10 in which the mean value and the standard deviation of the setup time distribution are much lower than those of Set 2 that consists of experiments 11-20. Dividing the experiments into two groups aims at validating that the utilization of the method proposed enables the user to detect low or high flexibility, regardless of the range of the setup times.

Moreover, the purpose of conducting a variety of experiments is to show that the FLEXIMAC method is capable of detecting even the smallest of differences in flexibility as well as to demonstrate that the degree of sensitivity to changes in setups, actually represent the system's flexibility. In principle, the higher the value of FLEXIMAC, the more flexible the system is considered.

\subsection{Set of experiments \#1}

In conducting these experiments:

- The setup times were assumed to be normally distributed with a mean value which varied from 5 to 8 , and a standard deviation which varied from 1 to 1.5 .

- The setups occurred every 10 or 20 completed operations 
The details of the experiments and the calculated FLEXIMAC values are provided in Table 1.

[Please insert Table 1 about here]

These results validate the FLEXIMAC method, since it is clear that when the setup time increases the flexibility of the system decreases. Table 2 shows the CPT/CFT plots of the recorded CPT and CFT values for experiments 1 to 5 , as well as the specifications for each experiment and the calculated FLEXIMAC value.

[Please insert Table 2 about here]

\subsection{Set of experiments \#2}

In these experiments:

- The setup times assigned to the departments have been assumed to be normally distributed with a mean value that varied from 35 to 70 , and a standard deviation varying from 5 to 6 .

- Setups were needed to take place every 100 or 150 completed machine operations.

The details of the experiments 11 to 20 and the calculated FLEXIMAC values are provided in Table 3.

[Please insert Table 3 about here]

These results again validate the FLEXIMAC method since it is clear that when the setup time increases the flexibility of the system decreases.

Furthermore, taking into consideration the fact that FLEXIMAC does not require complicated data, the task of collecting them is made easier. Both sets of experiments 
have validated that FLEXIMAC successfully measures the level of flexibility. Even small differences in the flexibility rating of each production system have been identified by FLEXIMAC.

\section{Industrial Case Studies}

In order to demonstrate the utilization of the proposed flexibility evaluation toolbox in real world production conditions, we will study two industrial cases in which different flexibility measures have been selected as the most appropriate ones in each case.

In the first case, the focus is on the typical problem of manufacturing system reconfiguration, a recurring challenge for the industry. Here, the flexibility toolbox is utilized to provide support in selecting the most suitable reconfiguration by evaluating the alternatives on the basis of flexibility. Specifically, two production lines (L1 and L2), are examined each of which produces a set of products. The demand for a specific product (Model F) is expected to be increasing in the following months, and the factory manager considers the reconfiguration of the lines as an option before this increase takes place in order to accommodate the new demands. A reconfiguration at this time would cost $150000 €$, while an urgent reconfiguration in the future would cost more. The problem has been summarized in the following Figure 7, where the manufacturing process is also presented.

[Please insert Figure 7 about here]

The two possible solutions are examined hereafter with the POC method being selected as the most appropriate for this case. Each solution has been examined in a timeframe of three periods. The following figure shows the scenario in which no reconfiguration 
takes place at the starting point. The probability and the switching cost are defined in each branch of the scenario, as shown in Figure 8.

[Please insert Figure 8 about here]

The POC for the previous scenario is calculated as $\mathrm{POC}_{\mathrm{A}}=0.8 * 250000+$ $0.8 * 0.2 * 100000+0.2 * 0.5 * 350000=200000+16000+35000=251000 €$

The next figure shows the scenario in which the production lines have been reconfigured at the starting point. The probability and the switching cost are defined in each branch of the scenario, as shown in Figure 9.

[Please insert Figure 9 about here]

The POC for this scenario is calculated as $\mathrm{POC}_{\mathrm{B}}=150000+0.2 * 100000+$ $0.8 * 0.2 * 100000+0.2 * 0.5 * 100000=150000+20000+16000+10000=196000 €$

Therefore, by utilizing the flexibility evaluation toolbox and the POC method, the engineer decides to apply the second solution.

In the second case, the engineer in charge wishes to evaluate the flexibility of a number of world-wide distributed production sites. Production data for 19 months has been collected and are used for the evaluation of flexibility. The data gathered include the operating hours of the final assembly line and the idle times when parts are waiting to be processed. These data recordings fit the requirements for the FLEXIMAC method. The three factories are located in Greece, Russia and Indonesia. The procedure followed for the flexibility evaluation is shown in Figure 10 and the data used for the evaluation is provided in Table 4.

[Please insert Figure 10 about here] 
[Please insert Table 4 about here]

By using the FLEXIMAC method we evaluate the flexibility of each site. The higher the value of FLEXIMAC the more flexible each factory may be considered. The following results are provided:

\section{FLEXIMAC (GREECE) $=0.4891$ \\ FLEXIMAC (RUSSIA) $\quad=\quad 0.4599$ \\ FLEXIMAC $($ INDONESIA $)=0.5408$}

The results of this evaluation aim to assist the engineers on monitoring and evaluating the company's production sites. The conclusions provide firstly, insight on the production systems, and secondly, a tool for decision making. The outcome of this assessment can be utilized in alternative ways to satisfy the different objectives.

To begin with, the results can be utilized in order for problematic areas to be detected and possible weaknesses in sites to be revealed before they become serious problems. The engineers responsible may have a more specific idea as to where possible upgrades and changes may be needed, from a very early stage, saving themselves time and effort. Additionally, the best practices can be identified and then can be applied to the other production sites to optimize their performance as well.

Furthermore, the results can also be utilized in order for production decisions to be supported. In cases of demand fluctuations, the production managers are called upon to formulate production programs in order to ensure demand satisfaction. Having attained substantiated information on the flexibility levels of the production sites, a clearer view on the production capabilities - in respect to capacity flexibility - of each factory is provided. Thus, the decision as to which product variants, in what quantities, and where they should be produced at, can be made on a safer basis, thus reducing the risk of the promised orders not to be delivered on time.

\section{Conclusions}

The implementation of the proposed approach is already in progress and the first prototypes are being tested. A number of different case studies, originating from real 
situations, provide the specifications of the final tests. It has to be stated, however, that the high expectations generated from the concept presented, create an important challenge for the final output. This challenge primarily is related to data quality and availability issues, which will become more concrete as the work continues.

The approach proposed is expected to become a significant asset to the production engineers and decision makers. The flexibility evaluation toolbox, comprising a number of different evaluation measures, the change management module, the openness of the platform and its ability to be integrated with existing ERP/IT systems and the variety of the front-end graphical user interfaces, are expected to cover a wide range of user requirements, addressing several different industrial domains.

Since flexibility is a subject with special properties and is in principle difficult to be quantified, the objectives of this work are: firstly, the successful introduction of semiautomated approaches for measuring flexibility in industrial environments and secondly, the consideration of flexibility indicators as characteristics of the production systems for decision-making.

\section{Acknowledgments}

This work has been partially funded by the European Commission through IST-NMPProject X-Change, Flexible Change Management for the Factory of the Future.

\section{References}

Abele, E., Liebeck, T., Worn, A, Measuring Flexibility in Investment Decisions for Manufacturing Systems, CIRP Annals, 2006, 55(1), pp. 433-436. 
Alexopoulos, K., A. Mamassioulas, A., Mourtzis, D. and Chryssolouris, G., Volume and Product Flexibility: a Case Study for a refrigerators Producing Facility, Proceedings of the 10th IEEE International Conference on Emerging Technologies and Factory Automation (ETFA 2005), Catania, Italy, (19-22 September 2005), 2005a, pp. 891-897.

Alexopoulos, K., Burkner, S., Milionis, I. and Chryssolouris, G., DESYMA - An integrated method to aid the design and the evaluation of reconfigurable manufacturing systems, Proceedings of the 1st International Conference on Changeable, Agile, Reconfigurable and Virtual Production (CARV 2005), Munich, Germany, (22-23 September 2005), 2005b, pp. 467-475.

Alexopoulos, K., Papakostas, N., Mourtzis, D., Gogos, P. and Chryssolouris, G., Quantifying the flexibility of a manufacturing system by applying the transfer function, International Journal of Computer Integrated Manufacturing, DOI: 10.1080/09511920600930046, 2006.

Alexopoulos, K., Mourtzis, D., Papakostas, N., and Chryssolouris, G., DESYMA Assessing flexibility for the lifecycle of manufacturing systems, International Journal of Production Research, 2007a, 45(7), pp. 1683-1694.

Alexopoulos, K., Papakostas, N., Mourtzis, D., Gogos, P. and Chryssolouris, G., Oscillator analogy for modelling the manufacturing systems dynamics, International Journal of Production Research, DOI: 10.1080/00207540601103118, $2007 \mathrm{~b}$.

Bateman, N., Stockton, D. J. and Lawrence, P., Measuring the mix response flexibility of manufacturing systems, International Journal of Production Research, 1999, 37, pp. $871-880$ 
Bechrakis, K., Karagiannis, S. and Chryssolouris, G., The $\zeta$ Analogy Method For The Modelling Of Manufacturing Systems, Proceedings of the Second World Congress on Intelligent Manufacturing Processes \& Systems, Budapest, Hungary, 10-13 June, 1997, pp. 166-169.

Carpanzano, E., Jovane, F., Advanced Automation Solutions for Future Adaptive Factories, CIRP Annals, 2007, 56(1), pp. 435-438.

Chryssolouris, G., Manufacturing Systems-Theory and Practice, 2nd Edition, 2005, (Springer-Verlag: New York).

Chryssolouris, G. and Lee M., An Assessment of Flexibility in Manufacturing Systems, Manufacturing Review, 1992, 5(2), pp.105-116.

Chryssolouris, G., Flexibility and Its Measurement, CIRP Annals, 1996, 45(2), pp. 581587.

Chryssolouris, G., Anifantis, N. and Karagiannis, S., An approach to the Dynamic Modelling of Manufacturing Systems, International Journal of Production Research, 1998, 36(2), pp. 475-483.

Colledanil M., Tolio T., A Decomposition Method to Support the Configuration / Reconfiguration of Production Systems, CIRP Annals, 2005, 54(1), pp 441- 444

Graves, S. and Tomlin, B., Process Flexibility in Supply Chains, Management Science, 2003, 49, pp. 907-919.

Georgoulias, K., Papakostas N., Makris S. and Chryssolouris G., A Toolbox Approach for Flexibility Measurements in Diverse Environments, Annals of CIRP, 2007, 56(1), pp. 423-426. 
Kochikar V.P., Narendran, T.T., A framework for assessing the flexibility of manufacturing systems, International Journal of Production Research, 1992, 30(12), pp.2873-95.

Mohamed, Z.M, Youssef, M.A:, Huq, F., The impact of machine flexibility on the performance of flexible manufacturing systems, International Journal of Operations and Production Management, 2001, 21(5/6), pp 707-742.

Peláez-Ibarrondo, J.J., and Ruiz-Mercader, J., Measuring Operational Flexibility, Proceedings of the Fourth SMESME International Conference, 2001

Pereira, J. and Paulré, B., Flexibility in manufacturing systems: A relational and a dynamic approach. European Journal of Operational Research, 2001, 130, pp. 7082.

Ramasesh, R., Kulkarni, S. and Jayakumar, M., Agility in manufacturing systems: An exploratory modeling framework and simulation. Integrated Manufacturing Systems, 2001, 12, pp. 534-548.

Schneeweiss, Ch., Kuhn, M., A quantitative measure for flexibility, Modern Production Concepts, 1991, pp.80-96 (Springer-Verlag, New York).

Shuiabia E., Thomson V. and Bhuiyan N., Entropy as a measure of operational flexibility, European Journal of Operational Research, 2005, 165(3), pp 696-707

Spicer, P., Koren, Y., Shpitalni, M. and Yip-Hoi, D., Design Principles for Machining Systems Configurations, CIRP Annals, 2002, 51(1), pp. 275-280.

Wahab, M.I.M., Desheng, (Dash) Wu, Chi-Guhn, Lee, A generic approach to measuring the machine flexibility of a manufacturing system, European Journal of Operational Research .2008, 186(1), pp. 137-149. 
Westkämper, E., Strategic Development of Factories under the Influence of Emerging Technologies, CIRP Annals, 2007, 56(1), pp. 419-422.

Wiendahl, H.P. and Heger, C.L., Justifying changeability. A methodological approach to achieving Cost Effectiveness. The manufacturing Journal for Manufacturing Science and Production, 2004, 6, pp. 33-39. 


\begin{tabular}{|c|c|c|}
\hline \multicolumn{2}{|c|}{ No of Operations=10 } \\
\hline Experiment \# & Setup Time & FLEXIMAC \\
\hline 1 & $\operatorname{Normal}(5,1)$ & 0,1396 \\
\hline 2 & $\operatorname{Normal}(6,1)$ & 0,1371 \\
\hline 3 & $\operatorname{Normal}(6,1.5)$ & 0,1343 \\
\hline 4 & $\operatorname{Normal}(7,1.5)$ & 0,1307 \\
\hline 5 & $\operatorname{Normal}(8,1.5)$ & 0,1271 \\
\hline No of Operations=20 & \multicolumn{2}{|c|}{} \\
\hline Experiment \# & Setup Time & FLEXIMAC \\
\hline 6 & Normal(8,1.5) & 0,1445 \\
\hline 7 & Normal(7,1.5) & 0,1471 \\
\hline 8 & $\operatorname{Normal}(6,1.5)$ & 0,1512 \\
\hline 9 & $\operatorname{Normal}(6,1)$ & 0,1532 \\
\hline 10 & $\operatorname{Normal}(5,1)$ & 0,1535 \\
\hline
\end{tabular}

Table 1: Specifications and FLEXIMAC results for experiments of Set \#1. 


\section{EXP. 1-5. CPT /CFT plots}

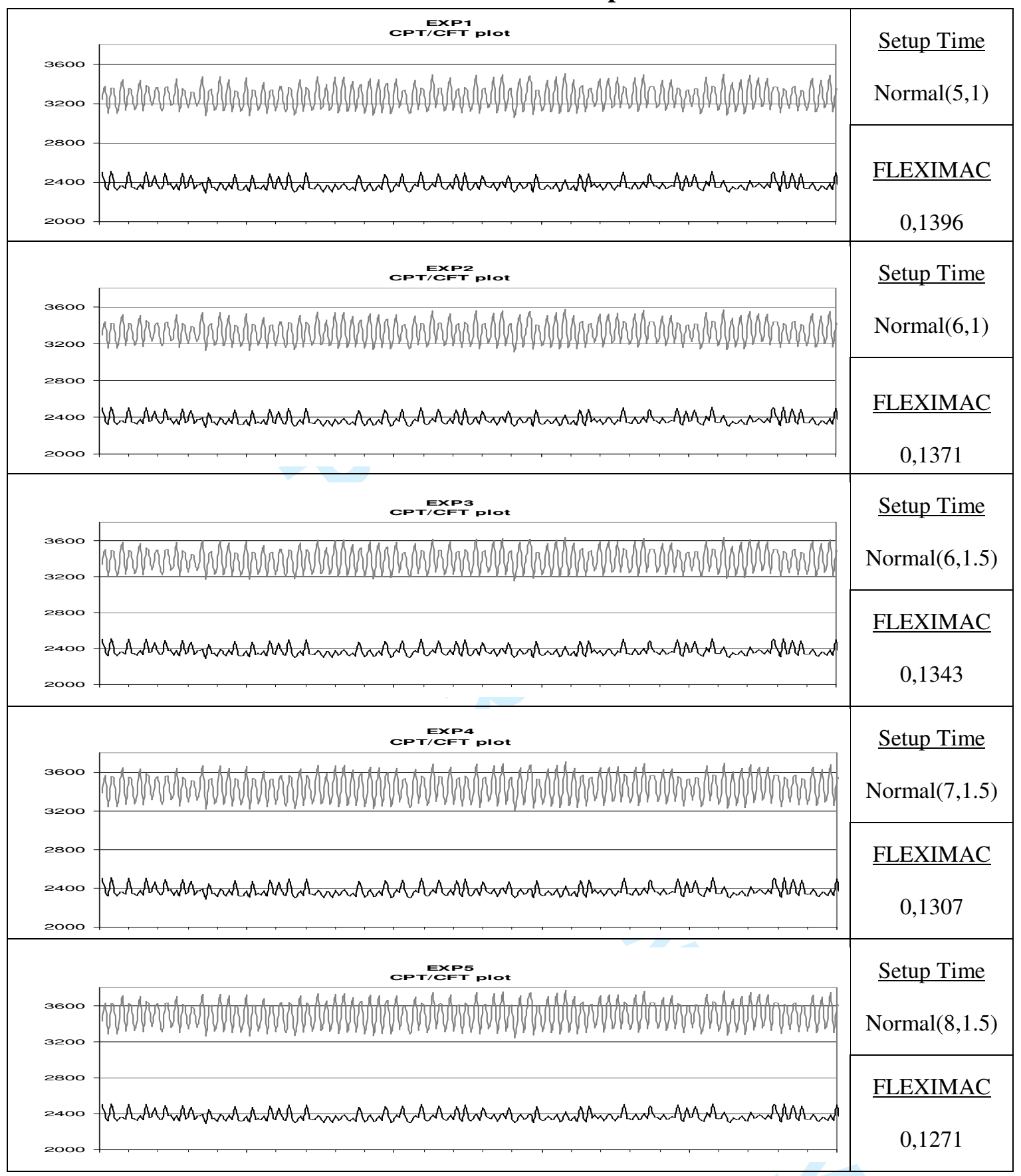

Table 2: Plots of CPT and CFT values for experiments 1 to 5. 


\begin{tabular}{|c|c|c|}
\hline \multicolumn{2}{|l|}{ No of Operations=100 } \\
\hline Experiment \# & Setup Time & FLEXIMAC \\
\hline 11 & Normal(35,5) & 0.0176 \\
\hline 12 & Normal(50,5) & 0,0121 \\
\hline 13 & Normal(60,5) & 0,0098 \\
\hline 14 & Normal(60,6) & 0,0095 \\
\hline 15 & Normal(70,6) & 0,0090 \\
\hline No of Operations=150 \\
\hline Experiment \# & Setup Time & FLEXIMAC \\
\hline 16 & Normal(35,5) & 0,0468 \\
\hline 17 & Normal(50,5) & 0,0449 \\
\hline 18 & Normal(60,5) & 0,0312 \\
\hline 19 & Normal(60,6) & 0,0228 \\
\hline 20 & Normal(70,6) & 0,0147 \\
\hline
\end{tabular}

Table 3: Specifications and FLEXIMAC results for experiments of Set \#2. 


\begin{tabular}{|c|c|c|c|c|c|c|c|c|c|}
\hline & \multicolumn{3}{|c|}{ GREECE } & \multicolumn{3}{|c|}{ RUSSIA } & \multicolumn{3}{|c|}{ INDONESIA } \\
\hline & $\begin{array}{l}\text { Operating } \\
\text { Line Hours }\end{array}$ & $\begin{array}{c}\text { Idle Tirne } \\
\%\end{array}$ & Total Hours & $\begin{array}{l}\text { Operating } \\
\text { Line Hours }\end{array}$ & $\begin{array}{c}\text { Idle Time } \\
\%\end{array}$ & Total Hours & $\begin{array}{l}\text { Operating } \\
\text { Line Hours }\end{array}$ & $\begin{array}{c}\text { Idle Time } \\
\%\end{array}$ & Total Hours \\
\hline M1 & 76.0 & 1.9 & 77.4 & 466.0 & 11.9 & 521.5 & 184.0 & 7.8 & 198.4 \\
\hline $\mathrm{M} 2$ & 396.0 & 4.2 & 412.6 & 642.0 & 10.3 & 708.1 & 294.0 & 14.4 & 336.3 \\
\hline M3 & 420.0 & 2.7 & 431.3 & 712.0 & 9.8 & 781.8 & 256.0 & 15.0 & 294.4 \\
\hline M4 & 260.0 & 2.7 & 267.0 & 753.0 & 13.4 & 853.9 & 461.0 & 14.3 & 526.9 \\
\hline M5 & 118.0 & 7.1 & 126.4 & 768.0 & 10.0 & 844.8 & 336.0 & 30.0 & 436.8 \\
\hline$M 6$ & 480.0 & 2.3 & 491.0 & 741.0 & 10.9 & 821.8 & 292.0 & 46.0 & 426.3 \\
\hline$M 7$ & 202.0 & 1.8 & 205.6 & 743.0 & 8.5 & 806.2 & 339.0 & 0.3 & 339.8 \\
\hline MB & 40.0 & 9.1 & 43.6 & 126.0 & 11.0 & 139.9 & 192.0 & 0.3 & 192.6 \\
\hline $\mathrm{M9}$ & 252.0 & 3.3 & 260.3 & 687.0 & 8.8 & 747.5 & 266.5 & 0.1 & 266.7 \\
\hline M10 & 389.0 & 2.3 & 397.9 & 749.0 & 7.4 & 804.4 & 195.8 & 0.2 & 196.1 \\
\hline M11 & 392.0 & 3.2 & 404.5 & 750.0 & 9.1 & 818.3 & 215.8 & 0.0 & 215.9 \\
\hline M12 & 184.0 & 5.2 & 193.6 & 750.0 & 8.7 & 815.3 & 231.0 & 0.1 & 231.2 \\
\hline M13 & 691.0 & 3.1 & 712.4 & 688.0 & 7.5 & 739.6 & 414.0 & 0.1 & 414.4 \\
\hline M14 & 676.0 & 2.2 & 690.9 & 691.0 & 6.3 & 734.5 & 486.7 & 0.1 & 487.4 \\
\hline M15 & 665.0 & 2.6 & 682.3 & 658.0 & 7.5 & 707.4 & 521.0 & 0.1 & 521.7 \\
\hline M16 & 821.0 & 1.8 & 835.8 & 761.0 & 7.3 & 816.6 & 424.5 & 0.0 & 424.7 \\
\hline M17 & 717.0 & 3.4 & 741.4 & 732.0 & 8.8 & 796.4 & 384.0 & 0.2 & 384.8 \\
\hline M18 & 337.0 & 2.6 & 345.8 & 753.0 & 8.1 & 814.0 & 353.0 & 0.2 & 353.7 \\
\hline M19 & 362.0 & 2.3 & 370.3 & 832.0 & 8.0 & 898.6 & 264.5 & 0.1 & 264.8 \\
\hline
\end{tabular}

Table 4: Production data gathered from the factories of Greece, Russia and Indonesia. 


\section{$\underline{\text { List of Figures }}$}

Figure 1: Overall technical approach

Figure 2: Flexibility Evaluation Toolbox

Figure 3: Flexibility Evaluation Process

Figure 4: Classification of flexibility measures

Figure 5: Flexibility Evaluation Toolbox in Change Management Process Figure 6: Simulated production system

Figure 7: Production line configuration and layout

Figure 8: Scenario with no reconfiguration implemented.

Figure 9: Scenario with reconfiguration implemented.

Figure 10: Flexibility evaluation of globally distributed production sites. 


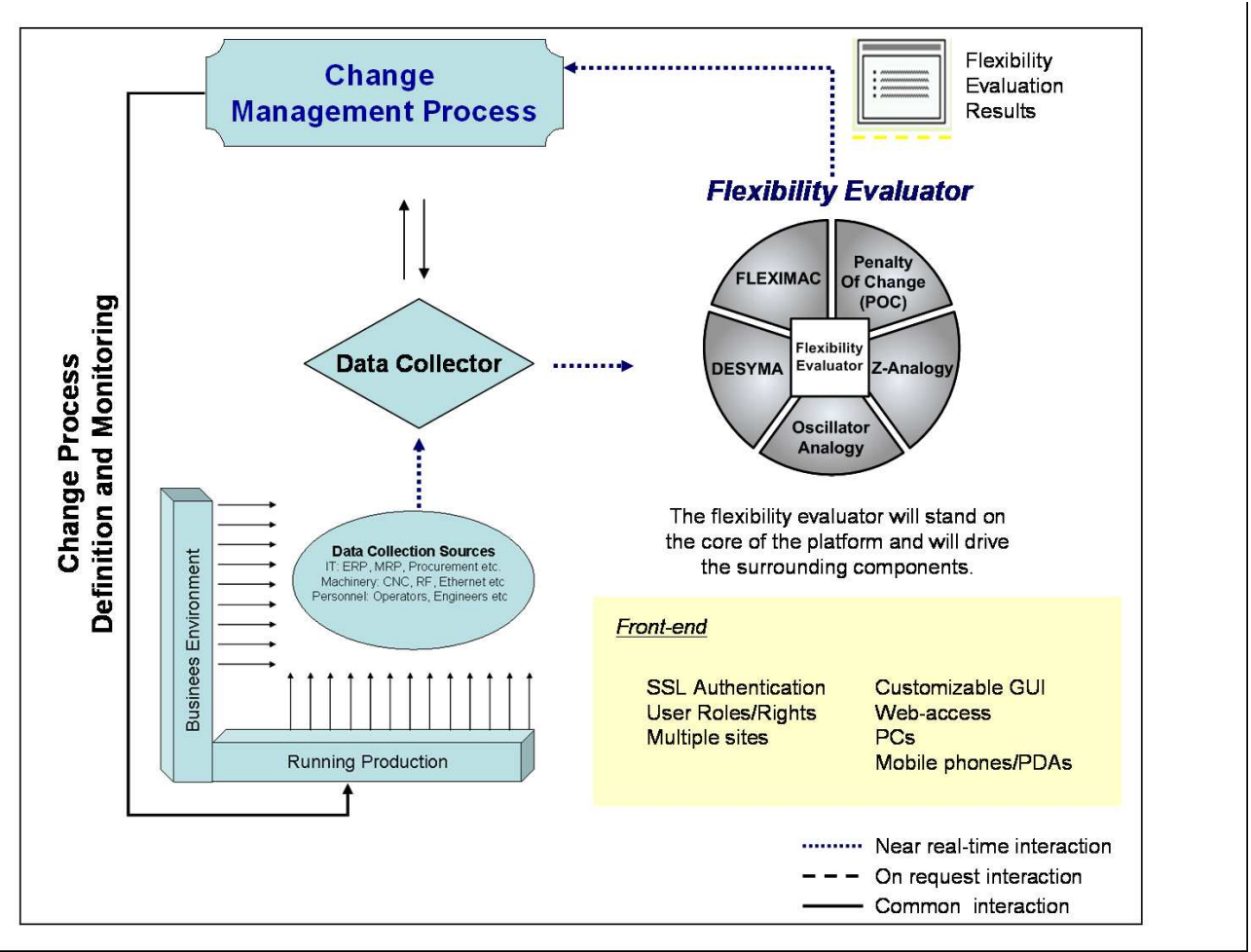

Figure 1: Overall technical approach $254 \times 190 \mathrm{~mm}(150 \times 150 \mathrm{DPI})$ 


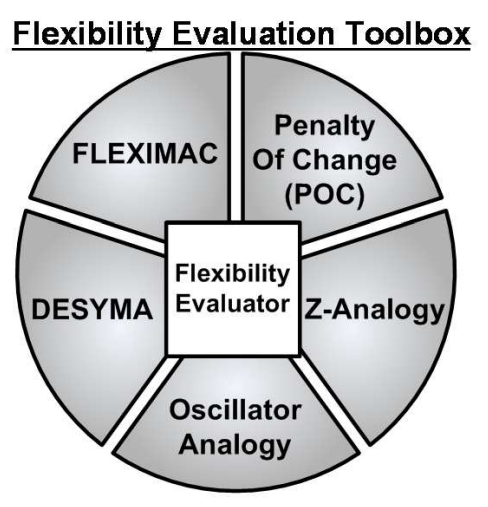

Integrated Flexibility Evaluation Measures

1. Penalty Of Change

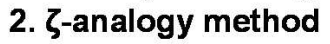

3. DESYMA

4. Oscillator analogy

5. FLEXIMAC

Figure 2: Flexibility Evaluation Toolbox $254 \times 190 \mathrm{~mm}(150 \times 150 \mathrm{DPI})$ 


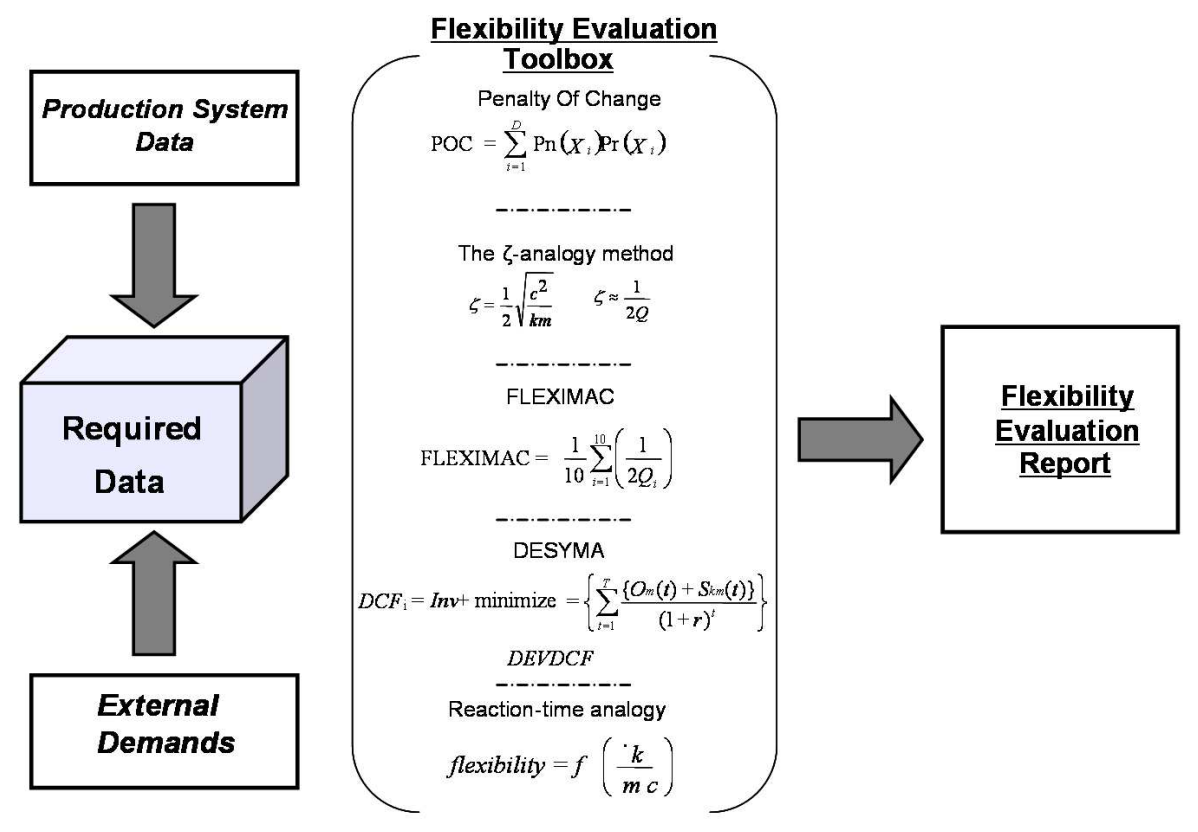

Figure 3: Flexibility Evaluation Process $254 \times 190 \mathrm{~mm}(150 \times 150 \mathrm{DPI})$ 


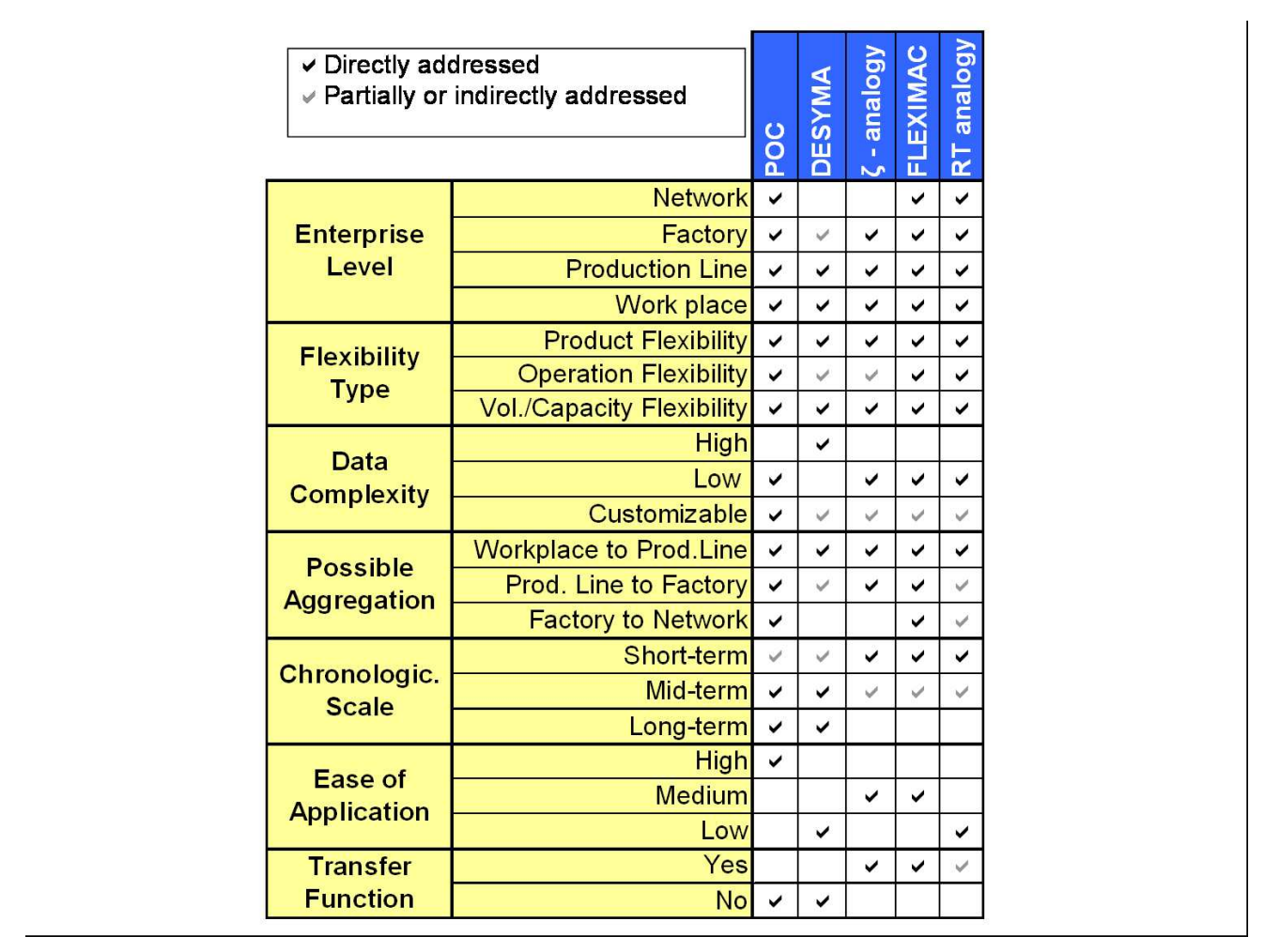

Figure 4: Classification of flexibility measures $254 \times 190 \mathrm{~mm}(150 \times 150 \mathrm{DPI})$ 


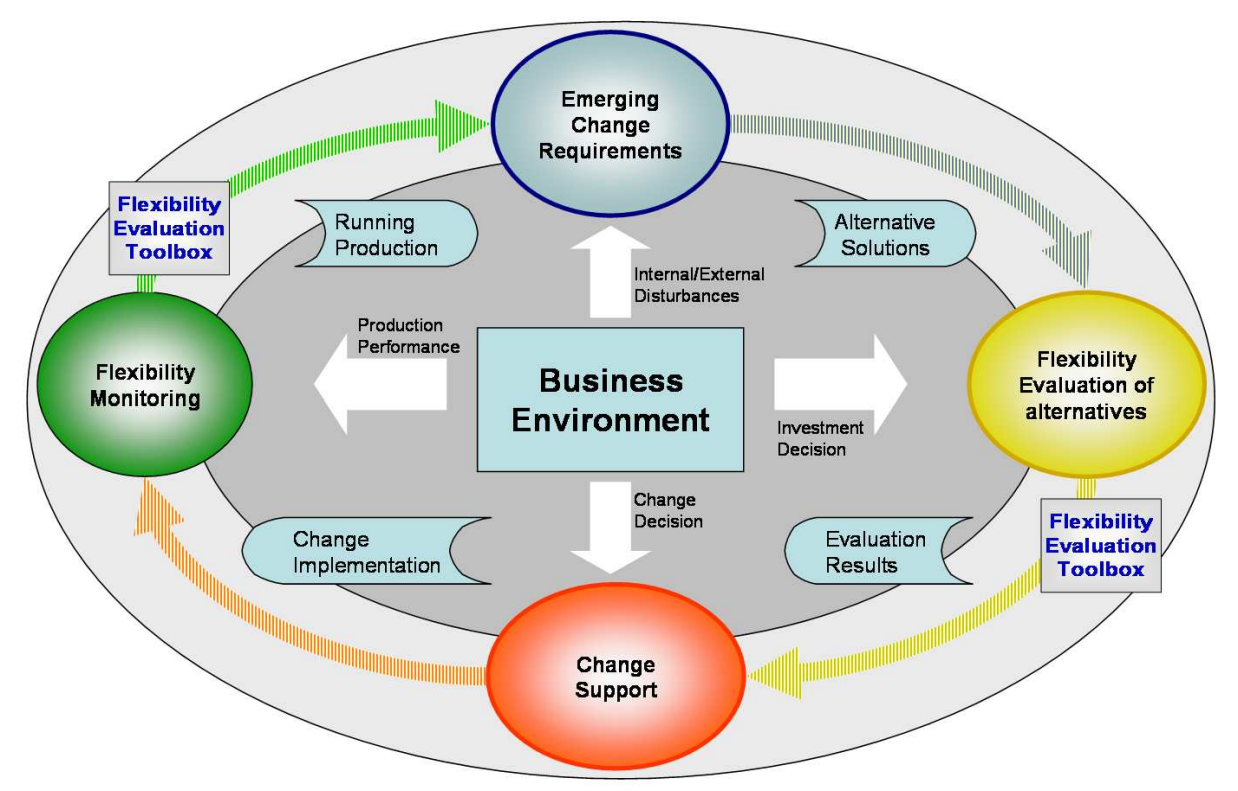

Figure 5: Flexibility Evaluation Toolbox in Change Management Process $254 \times 190 \mathrm{~mm}(150 \times 150$ DPI $)$ 


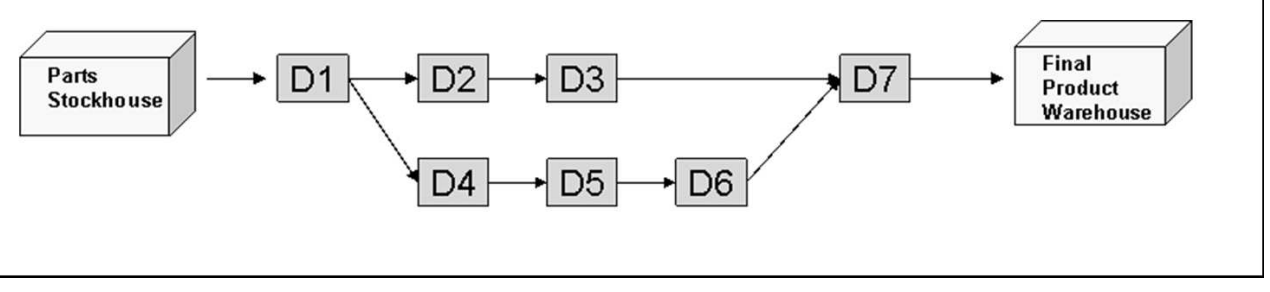

Figure 6: Simulated production system $254 \times 60 \mathrm{~mm}(150 \times 150 \mathrm{DPI})$ 


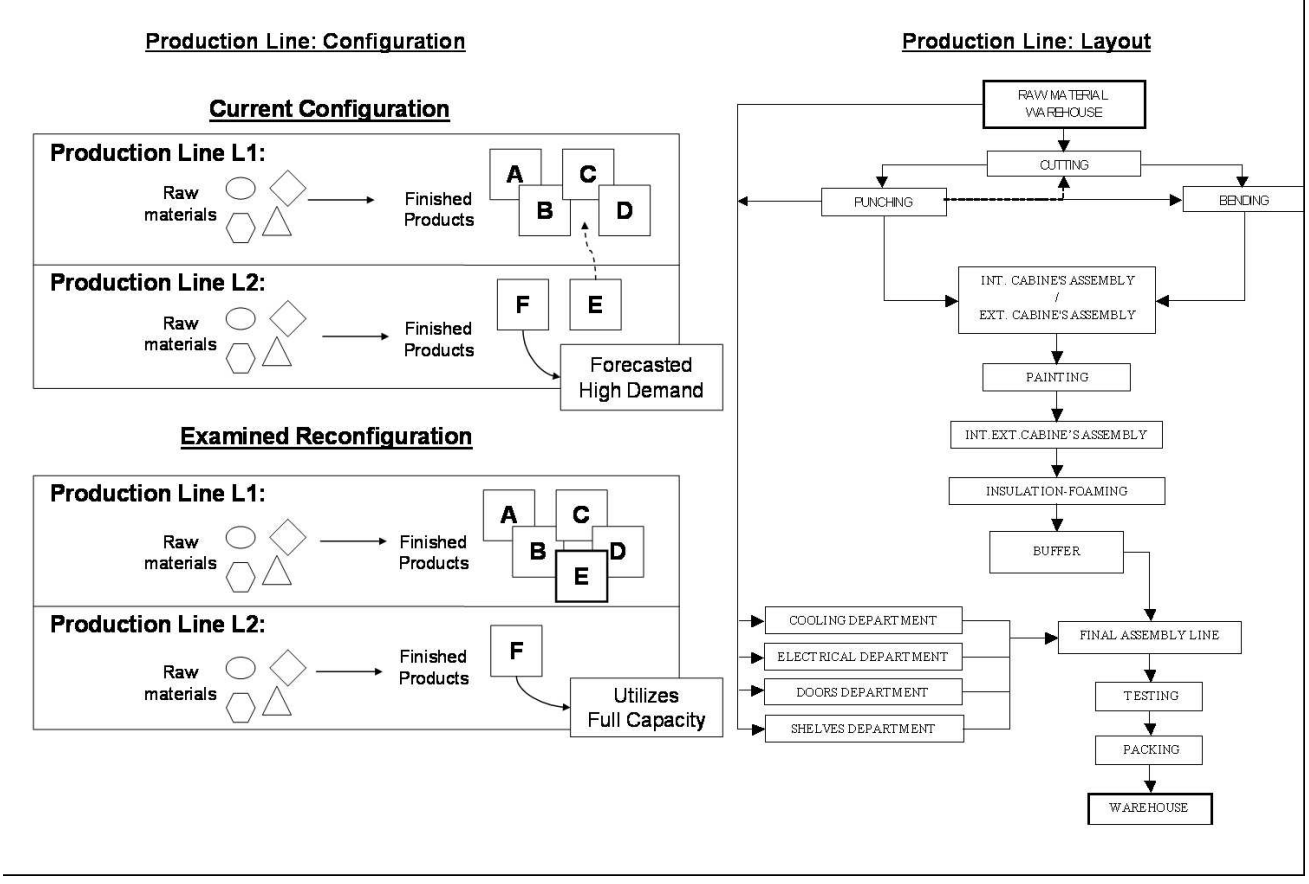

Figure 7: Production line configuration and layout $254 \times 190 \mathrm{~mm}(150 \times 150 \mathrm{DPI})$ 


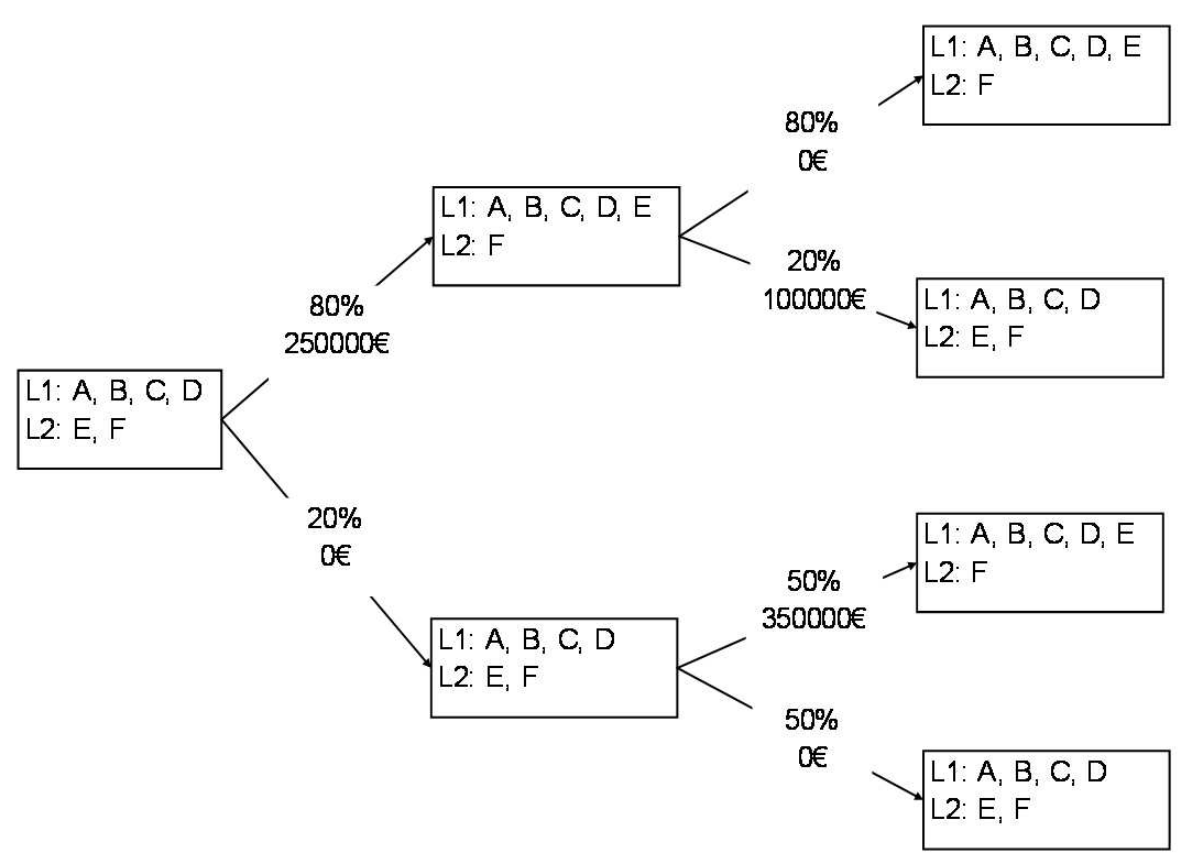

Figure 8: Scenario with no reconfiguration implemented. $200 \times 160 \mathrm{~mm}(150 \times 150 \mathrm{DPI})$ 


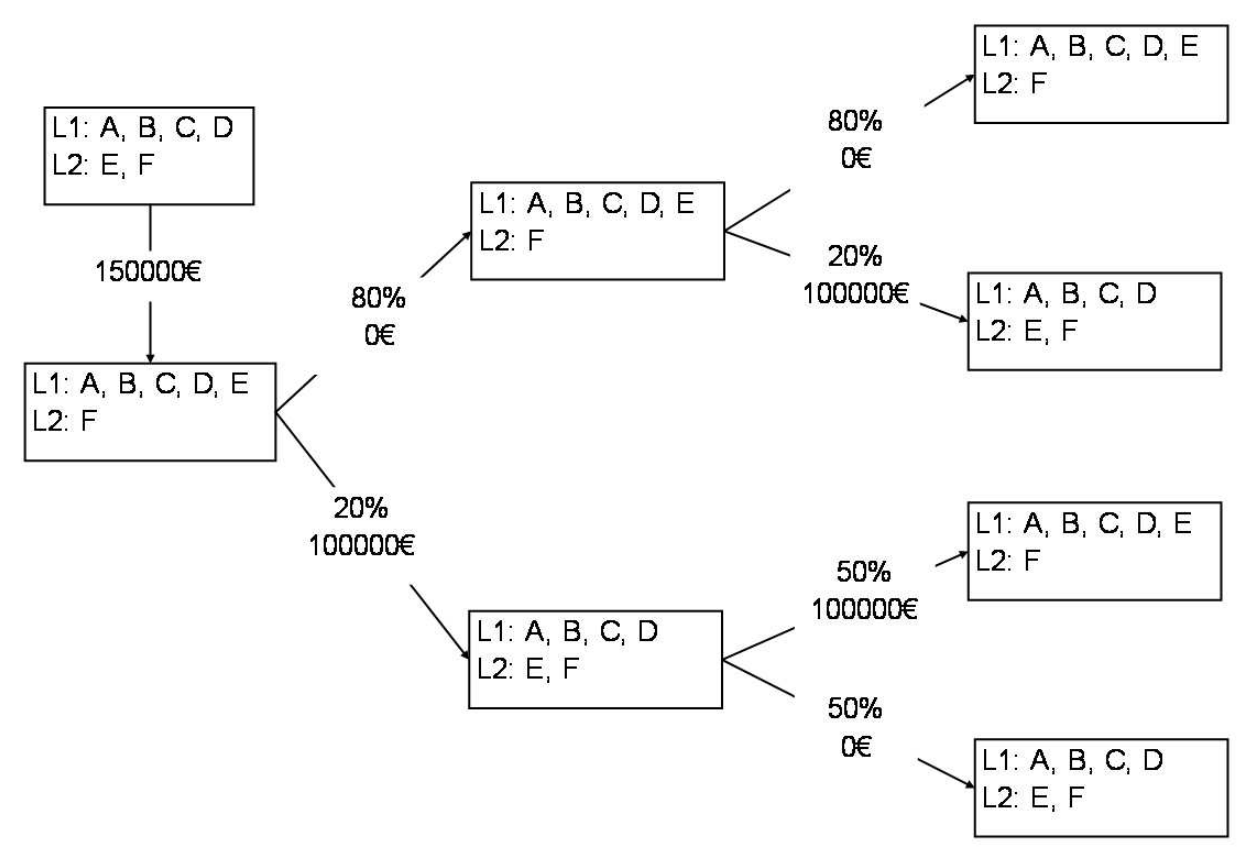

Figure 9: Scenario with reconfiguration implemented. $200 \times 160 \mathrm{~mm}(150 \times 150 \mathrm{DPI})$ 


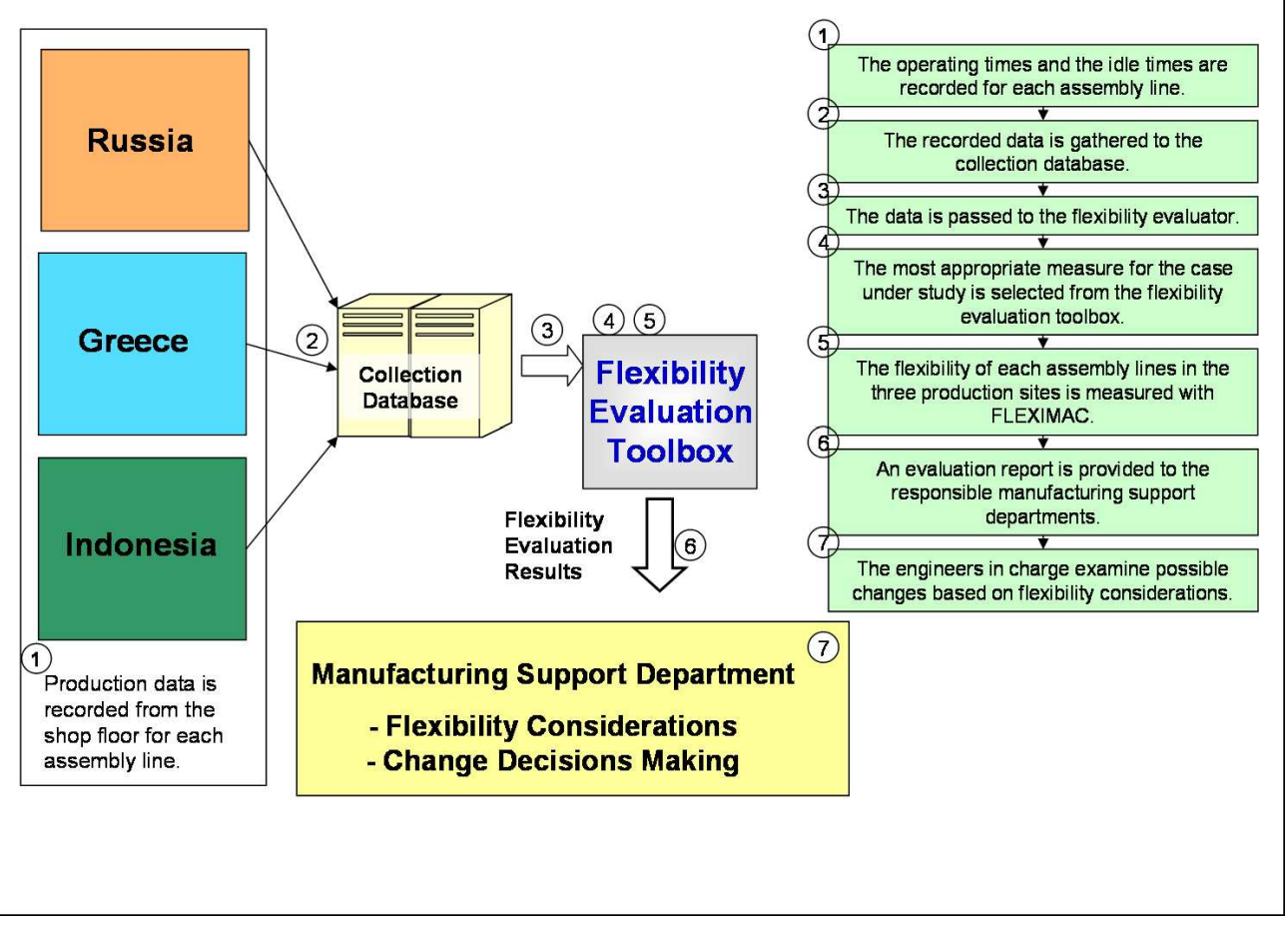

Figure 10: Flexibility evaluation of globally distributed production sites. $254 \times 190 \mathrm{~mm}(150 \times 150 \mathrm{DPI})$ 